\title{
OPEN Formation and characterization of lipid droplets of the bovine corpus luteum
}

\begin{abstract}
Heather A. Talbott ${ }^{1,2,6,8}$, Michele R. Plewes ${ }^{1,3,8}$, Crystal Krause ${ }^{1,7}$, Xiaoying Hou ${ }^{1}$, Pan Zhang ${ }^{1}$, William B. Rizzo ${ }^{4}$, Jennifer R. Wood ${ }^{5}$, Andrea S. Cupp ${ }^{5}$ \& John S. Davis ${ }^{1,2,3 凶}$

Establishment and maintenance of pregnancy depends on progesterone synthesized by luteal tissue in the ovary. Our objective was to identify the characteristics of lipid droplets (LDs) in ovarian steroidogenic cells. We hypothesized that LDs are a major feature of steroidogenic luteal cells and store cholesteryl esters. Whole bovine tissues, isolated ovarian steroidogenic cells (granulosa, theca, small luteal, and large luteal), and isolated luteal LDs were assessed for LD content, LD-associated proteins and lipid analyses. Bovine luteal tissue contained abundant lipid droplets, LD-associated perilipins 2/3/5, hormone-sensitive lipase, and 1-acylglycerol-3-phosphate 0-acyltransferase ABHD5. Luteal tissue was enriched in triglycerides (TGs) compared to other tissues, except for adipose tissue. Luteal cells were distinguishable from follicular cells by the presence of LDs, LD-associated proteins, and increased TGs. Furthermore, LDs from large luteal cells were numerous and small; whereas, LDs from small luteal cells were large and less numerous. Isolated LDs contained nearly all of the TGs and cholesteryl esters present in luteal tissue. Isolated luteal LDs were composed primarily of TG, with lesser amounts of cholesteryl esters, diglyceride and other phospholipids. Bovine luteal LDs are distinct from LDs in other bovine tissues, including follicular steroidogenic cells.
\end{abstract}

Luteal tissue forms in the ovary during each estrus or menstrual cycle and synthesizes progesterone, a steroid critical for early embryonic development and survival during pregnancy ${ }^{1,2}$. Luteal tissue has a tremendous ability to synthesize progesterone, secreting up to $40 \mathrm{mg} /$ day in humans ${ }^{3}$, and even greater quantities in cattle ${ }^{4}$. The majority of the cholesterol utilized for progesterone biosynthesis in cattle comes from the blood in the form of high-density lipoprotein-derived cholesteryl esters with smaller amounts from low-density lipoprotein ${ }^{5}$. Lipoproteins are internalized either through receptor-mediated endocytosis or selective cellular uptake, where cholesterol is sorted from lipoproteins within endosomes ${ }^{5}$. Endosomal cholesterol is then believed to be trafficked to mitochondria for immediate progesterone biosynthesis or stored as cholesteryl esters in lipid reservoirs, also known as lipid droplets (LDs) for future steroid biosynthesis ${ }^{5,6}$. In addition to its vital role in mammalian fertility, progesterone is an essential precursor of androgens, estrogens, glucocorticoids and mineralocorticoids. Therefore, the high steroidogenic output of luteal tissue allows for detailed studies of steroidogenic mechanisms, which are likely conserved among steroidogenic cell types.

LDs store neutral lipids and are coated with LD-associated proteins that embed within the surrounding phospholipid monolayer. These LD-associated proteins stabilize the LD, interact with additional proteins that incorporate or remove lipids from the LD core, enable LD trafficking, and mediate association of LDs with other organelles ${ }^{7}$. The perilipin (PLIN) proteins, designated PLIN1-5, are a family of LD coat proteins that are important for stabilizing LD structure and provide a platform for protein assembly on the LD surface ${ }^{7}$. Although LDs have been observed in nearly all tissues, LDs have been most extensively studied in adipose cells, where they form large unilocular droplets ${ }^{7}$. In many circumstances, the formation of LDs is a sign of pathological conditions, such as the cholesteryl ester-laden foamy macrophage in atherosclerotic lesions ${ }^{8}$, fatty liver disease due to liver

${ }^{1}$ Department of Obstetrics and Gynecology, Olson Center for Women's Health, University of Nebraska Medical Center, Omaha, NE 68198-9450, USA. ²Department of Biochemistry and Molecular Biology, University of Nebraska Medical Center, Omaha, NE 68198-5870, USA. ${ }^{3}$ Veterans Affairs Nebraska-Western lowa Health Care System, Omaha, NE 68105, USA. "'Department of Pediatrics, University of Nebraska Medical Center, Omaha, NE 68198-5940, USA. ${ }^{5}$ Department of Animal Science, University of Nebraska-Lincoln, Lincoln, NE 68583-0908, USA. ${ }^{6}$ Present address: Division of Reproductive and Developmental Sciences, Oregon Health Sciences University/Oregon National Primate Research Center, Beaverton, OR 97006, USA. ${ }^{7}$ Present address: Surgery Department, University of Nebraska Medical Center, Omaha, NE 68198-3280, USA. ${ }^{8}$ These authors contributed equally: Heather A. Talbott and Michele R. Plewes. ${ }^{\circledR}$ email: jsdavis@unmc.edu 
damage $e^{9,10}$, or adiposity due to storage of excess lipids ${ }^{11}$. However, in steroidogenic tissues, such as the ovary, LDs are a prominent and generally non-pathogenic feature-except in cases of genetic disorders of steroidogenesis ${ }^{12}$. Herein, we provide the first characterization of LD-associated proteins and lipases expressed in ovarian LDs.

Ovarian luteal tissue is easily distinguished from other tissues due to the abundant lipid content and cytoplasmic LDs. Luteal LDs exist in all species examined to date including: mice ${ }^{13}$, rats $^{14}$, sheep ${ }^{15}$, cattle $^{16}$, pigs ${ }^{17}$, buffalo $^{18}$, rabbits $^{19}$, bats $^{20}$, non-human primates ${ }^{21}$, and humans ${ }^{22}$. The presence of LDs is used to distinguish active steroid-secreting luteal cells and luteal LDs are reported to contain both cholesterol and cholesteryl esters that can be used to synthesize steroids in both humans and cattle ${ }^{23,24}$. Strikingly, in rats and rabbits, luteal LDs are primarily composed of cholesteryl esters, and stimulation of steroid synthesis reduces LD cholesteryl ester concentrations ${ }^{25}$. Luteal LD presence and composition are known to be regulated by luteal trophic hormones, like luteinizing hormone, which decreases LD content ${ }^{25}$, luteolytic hormones, like prostaglandin F $2 \alpha$, that increase LD content ${ }^{26}$, and by $\operatorname{diet}^{27}$. With the knowledge of LD-associated proteins and lipids in other tissues, we set out to characterize LD features within the bovine luteal tissue, while it was actively secreting progesterone. Herein, we provide a comprehensive characterization of bovine luteal LDs. The present study compares luteal LDs to LDs in other tissues (adipose, hepatic, and cardiac) with differing metabolic profiles. This study provides the first characterization of LDs in large and small steroidogenic luteal cells, and provides a comprehensive analysis of the phospholipid and neutral lipid composition of luteal LDs.

\section{Results}

Visualization and quantification of luteal tissue LDs. Functional bovine luteal tissue prominently featured LDs, which occupied the majority of luteal tissue, consistent with steroidogenic cell distribution within luteal tissue. However, vasculature and connective tissue invaginations within the luteal tissue (composed of non-steroidogenic endothelial and fibroblast cells) contained few LDs (Fig. 1A). Luteal LDs, stained with oil red O, occupied an average area of $29.9 \pm 8.56 \mu \mathrm{m}^{2}$ per nucleus within luteal tissue sections (Fig. 1A,B). Additionally, luteal LDs were an abundant ultrastructural feature of functional luteal tissue and were often in close proximity with mitochondria (Fig. 1C). Individual LDs occupied an average area of $0.41 \pm 0.04 \mu \mathrm{m}^{2}$ in luteal tissue corresponding to an average diameter of $\sim 0.72 \mu \mathrm{m}$ and a range of $0.16-1.8 \mu \mathrm{m}^{2}$ (Fig. 1C,D). Moreover, luteal LDs are present within the steroidogenic cells of luteal tissue, as confirmed by BODIPY-labeled LDs co-localized with a marker of steroidogenic cells, 3 beta-hydroxysteroid dehydrogenase/Delta 5->4-isomerase type 1 (Fig. 1E).

Luteal tissue compared to other LD-associated tissues. Bovine luteal tissue had a distinct composition of LD-associated proteins compared to other tissues (Fig. 2A). Luteal tissue contained considerable PLIN2 and PLIN5 protein, little to no PLIN1, and a moderate amount of PLIN3. In contrast, visceral adipose tissue had abundant PLIN1, hepatic tissue expressed PLIN2, and cardiac tissue had high amounts of PLIN2, PLIN3, and PLIN5. Bovine luteal tissue expressed substantial amounts of lipid-modifying enzymes: hormone sensitive lipase, 1-acylglycerol-3-phosphate O-acyltransferase abhydrolase domain containing 5 (ABHD5), and lesser amounts of adipose triglyceride lipase (aka, patatin-like phospholipase domain-containing protein 2) and sterol $\mathrm{O}$-acyltransferase 1 . Hepatic tissue had the most sterol O-acyltransferase 1 and also expressed but had little hormone sensitive lipase and adipose triglyceride lipase. Adipose tissue had the most hormone sensitive lipase, large amounts of adipose triglyceride lipase, and less sterol O-acyltransferase than cardiac or hepatic tissue. Finally, cardiac tissue had large amounts of adipose triglyceride lipase, intermediate amounts of sterol O-acyltransferase, and a small amount of hormone sensitive lipase. Additionally, luteal tissue had a unique lipid composition, which is particularly evident in the high triglyceride (TG) content compared to pulmonary, hepatic, and cardiac tissue (Fig. 2B). Adipose tissue, as expected, had nearly 100-fold more TG than other tissues. Cholesteryl esters were a minor lipid class in all tissues investigated, and cholesteryl ester levels were nearly absent in bovine cardiac tissue. Sterol abundance was lowest in cardiac tissue and highest in adipose tissue; whereas, free fatty acids were highest in adipose tissue (fourfold), followed by hepatic tissue.

Comparison of follicular and luteal cell type LD features. Follicular granulosa and theca cells differentiate to give rise to large and small luteal cells after ovulation ${ }^{28}$. LD content was compared between the follicular and luteal cell types. Granulosa and theca cells had fewer and smaller LDs than the luteal cell types, as assessed by BODIPY staining of LDs and confocal imaging (Fig. 3A). Cytoplasmic staining for aromatase confirmed the identity of granulosa cells. A microarray comparison ${ }^{29}$ between granulosa, theca, large luteal cells and small luteal cells indicated that mRNA abundance of LD-associated proteins PLIN2, PLIN3 and hormone sensitive lipase (LIPE) were increased in luteal cell types compared to follicular cells (Fig. 3B). Similarly, mixed luteal cells and both small and large luteal cells had greater amounts of hormone sensitive lipase compared to granulosa and theca cell isolates, along with greater expression of steroidogenic enzymes: Steroidogenic acute regulatory protein, cholesterol side-chain cleavage enzyme, and 3 beta-hydroxysteroid dehydrogenase/ Delta 5-> 4-isomerase type 1 (Fig. 3C). These data indicate that during differentiation of ovarian follicular cells (granulosa and theca) into luteal cells (large and small luteal cells) there are parallel increases in LDs and steroidogenic enzymes (Fig. 3D). Additionally, granulosa cells contained more TG, sterols, and free fatty acids than theca cells. Moreover, large and small luteal cells had more TG than granulosa or theca cells, as determined by high-performance thin-layer chromatography (Fig. 3E).

Khor et al. suggest that cholesterol and TG can segregate into distinct LD populations ${ }^{30}$. Large luteal cell and small luteal cells both had substantial (>90\%) colocalization of fluorescently-labeled cholesterols and fatty acids within LDs, as examined by confocal microscopy (Fig. 4A,B). Large luteal cells had significantly more LDs $(271 \pm 22)$ compared to small luteal cells $(89 \pm 8)$ (Fig. 4C,E); whereas, small luteal cell LDs were significantly greater in volume $\left(695.5 \pm 112.3 \mathrm{~nm}^{3}\right)$ than large luteal cell LDs $\left(293.2 \pm 39 \mathrm{~nm}^{3}\right.$, Fig. 4B,C), visualized by confocal 
A

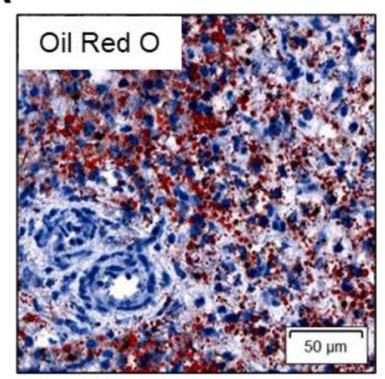

C

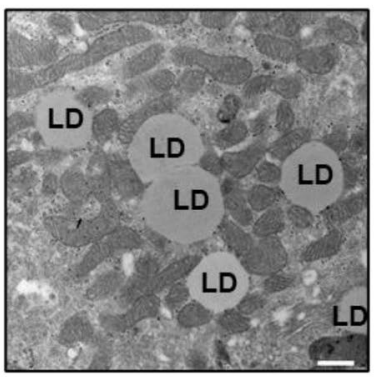

$\mathbf{E}$

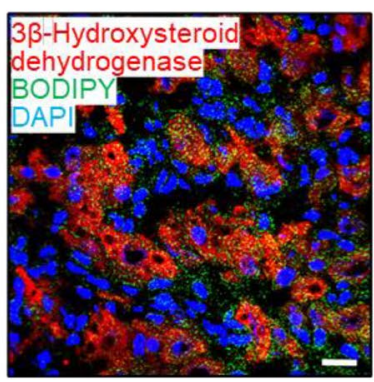

B

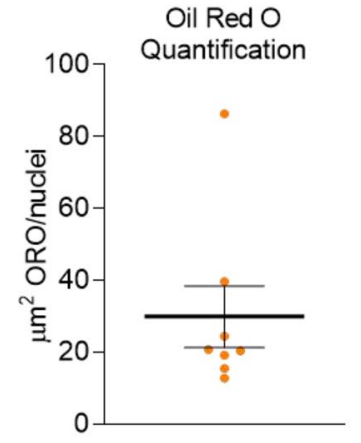

D

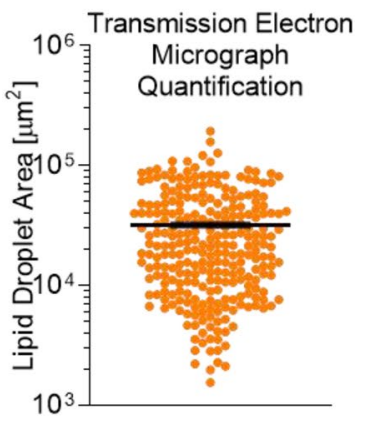

Figure 1. Visualization of luteal LDs. Luteal LDs were visualized using oil red O staining, transmission electron micrographs, and confocal microscopy. Panel (A) Oil red O staining (red) of lipids in frozen tissue sections of functional bovine corpus luteum counterstained with hematoxylin (blue). Representative image shown at $40 \times$, scale bar $=50 \mu \mathrm{m}$. Panel (B) Automated quantification of tissue area occupied by oil red O staining, each point demonstrates the area $\left(\mu \mathrm{m}^{2}\right)$ occupied by red immunohistochemistry staining in three randomly chosen images per animal ( $n=6$, mean \pm SEM indicated with black lines). Panel (C) Transmission electron micrograph of bovine luteal tissue demonstrating multiple LDs (labeled LD) surrounded by mitochondria. Representative image shown at $21,000 \times$, scale bar $=500 \mathrm{~nm}$. Panel (D) Logarithmic graph of the quantification of area $\left(\mu \mathrm{m}^{2}\right)$ occupied by individual LDs in three randomly chosen images per animal $(n=6$, mean \pm SEM are indicated with a black line). Panel (E) Representative confocal image obtained from frozen tissue sections of functional luteal tissue co-labeled with BODIPY493/503 (green; LD), HSD3B (red; marker for steroidogenic cells), and 4',6-diamidino-2-phenylindole (DAPI, blue). Representative image shown at $63 \times$, scale bar $=20 \mu \mathrm{m}$.

microscopy. The measured LD volumes correspond to an average LD diameter of $1.1 \mu \mathrm{M}$ for small luteal cells and $0.82 \mu \mathrm{M}$ for large luteal cells. In agreement with volume measurements, small luteal cells had more lipid content than large luteal cells as measured using mean fluorescence intensity to estimate the total lipid content (Fig. 4D,F).

Composition of isolated luteal LDs. Isolated luteal LDs, prepared by a step-wise sucrose gradient, were yellow in color in comparison to LDs from other tissues (Fig. 5A). Intact LDs, imaged by transmission electron microscopy, were relatively free from other cellular organelles and debris after isolation (Fig. 5B). The cellular localization of lipid classes in the total luteal tissue fraction, the isolated LD fraction, and the LD-depleted fraction were compared using high-performance thin layer chromatography (Fig. 5C). TGs were primarily stored in luteal LDs, with nearly no TG found in LD-depleted lysates. Similarly, cholesteryl esters were present in the LD fraction and absent in LD-depleted lysates. Sterols and free fatty acids showed little segregation between LDs and LD-depleted cellular fractions. Lipid extracts of LDs were characteristically yellow which deepened in color during concentration of LDs and of LD lipids. During high-performance thin layer chromatography a yellow band, presumably carotenes, consistently migrated along the solvent front with cholesteryl esters (not shown). Additionally, a band of unknown lipid species consistently migrated between the TG and cholesteryl ester stand- 
A

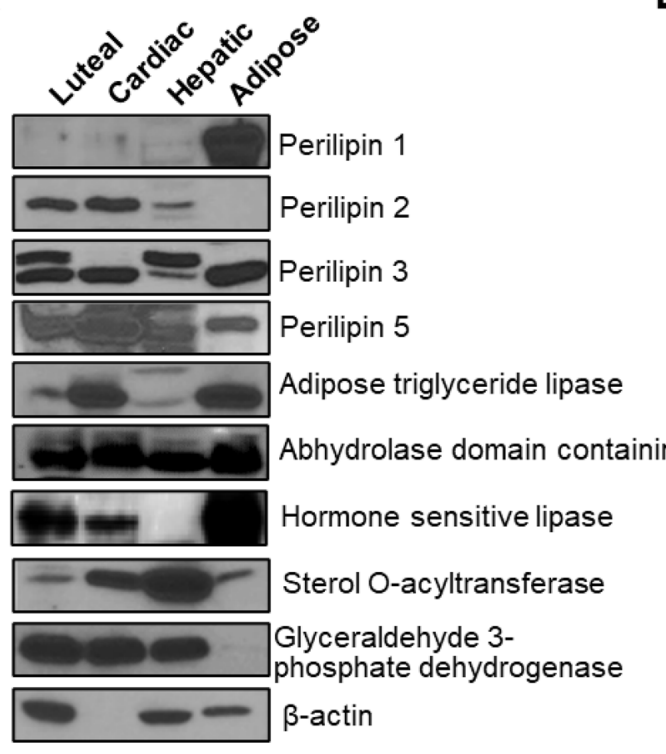

B
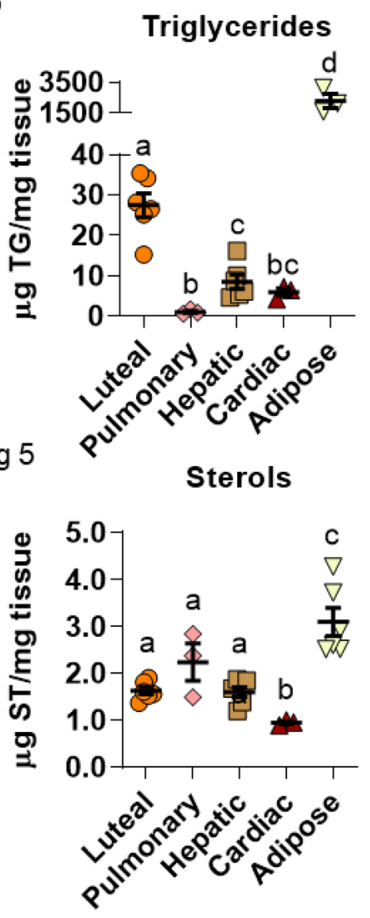

Cholesteryl Esters

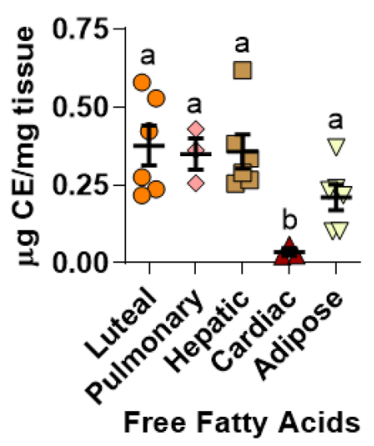

Figure 2. Lipid droplet (LD)-associated protein and lipid content of luteal tissue. Bovine luteal, cardiac, hepatic, pulmonary and visceral adipose tissues were collected to compare LD-associated protein and lipid content of luteal tissue between LD associated tissues. Panel (A) The presence of the LD-coat proteins (PLIN 1, 2, 3, and 5), key neutral lipid hydrolysis enzymes (ATGL, ABHD5, HSL), lipid forming enzymes (SOAT1) and loading controls ( $\beta$-actin \& GAPDH) were assessed by western blot. Panel (B) Lipid content of luteal tissue $(n=6)$ in comparison to pulmonary $(n=3)$, hepatic $(n=6)$, cardiac $(n=3)$, and visceral adipose tissue $(n=6)$ was determined by high-performance thin layer chromatography analysis to assess relative amounts of major neutral lipid classes. Horizontal line and error bars indicate mean \pm SEM, significance was determined using mixedeffects model (factor 1: cell type (unmatched), factor 2: lipid class (matched)) after log transformation of values and Tukey's multiple comparisons test. Means with different letters differ significantly between tissues $(P<0.05)$.

ards when separated by high-performance thin layer chromatography (not shown), possibly ether-linked lipids, which have been reported in adiposome $\mathrm{LDs}^{31}$.

Lipidomics analysis of three different preparations of luteal tissue LDs confirmed that luteal LDs are primarily composed of TG ( $168 \pm 42 \mathrm{pmol} / \mu \mathrm{g}$ protein, $89 \mathrm{~mol} \%$ of total lipids) but also contain many other lipid classes (Fig. 6A). Other neutral lipids included diglycerides (DGs; $5.7 \pm 2.1 \mathrm{pmol} / \mu \mathrm{g}$ protein, $2.9 \%$ ); and cholesteryl esters $(3.65 \pm 0.7 \mathrm{pmol} / \mu \mathrm{g}$ protein, $2.0 \%)$. Polar lipids were primarily composed of phosphatidylcholines (PC; $3.9 \pm 0.8 \mathrm{pmol} / \mu \mathrm{g}$ protein, $2.2 \%)$, sphingomyelins $(2.7 \pm 0.3 \mathrm{pmol} / \mu \mathrm{g}$ protein, $1.5 \%)$, phosphatidylinositols $(1.7 \pm 0.6 \mathrm{pmol} / \mu \mathrm{g}$ protein, $0.9 \%)$, phosphatidylethanolamines $(1.4 \pm 0.4 \mathrm{pmol} / \mu \mathrm{g}$ protein, $0.8 \%)$ and phosphatidylserines $(0.65 \pm 0.04 \mathrm{pmol} / \mu \mathrm{g}$ protein, $0.4 \%)$. A number of other minor lipids representing less than $0.33 \mathrm{~mol} \%$ of the total lipid pool were also detected including phosphatidylglycerol, lysophosphatidylinositol, lysophosphatidylcholine, lysophosphatidylethanolamine, lysophosphatidylserine, ceramides, glucosylceramides, and sphingoid bases (Fig. 6A). Sterols were below the limit of detection (lowest concentration of standard curve) in all three LD samples. The polar to nonpolar lipid ratio was $7.12 \pm 0.017$, which corresponds to an average $\mathrm{LD}$ diameter of $282 \mathrm{~nm}$ if the properties of sphericity and surface area to volume ratios are used to calculate the expected LD diameter ${ }^{32}$.

Each lipid class was composed of a diversity of fatty acyl species. The TG class was represented by 28 species, of which 26 molecular species were found in all three samples (Fig. 6B). Four principal groups with 52, 56, 54, and 50 acyl carbons were detected, each with a number of double bonds. The predominant species was 52:2 (total acyl carbons:total acyl double bonds) representing $~ 14 \mathrm{~mol} \%$ of the TG class; and the combination of TG(52:3), TG(56:8), TG(54:3), TG(56:7), and TG(50:1) species represented 39\% of TGs. The DG class was represented by 30 molecular species (29 detected in all three samples) (Fig. 6C). Three principal DG groups with 32, 34 and 36 acyl carbons were identified, none of which contained double bonds. Approximately $58 \%$ of the DG pool was composed of the DG(32:0), DG(34:0), and DG(36:0) species. The cholesteryl ester class was composed of 20 molecular species (all species were detected in all samples) (Fig. 6D) with four principal cholesteryl ester-linked fatty acid moieties: (18:1), (20:4), (22:4) and (22:5) which made up 60\% of cholesteryl esters.

The luteal LD phospholipid composition (expressed as a percentage of total phospholipid) was predominately PC (37\%) followed by sphingomyelin (26\%), phosphatidylinositol (15\%), phosphatidylethanolamine (13\%), phosphatidylserine $(7 \%)$ and phosphatidylglycerol $(0.8 \%)$, while lysophospholipids only accounted for $1.4 \%$ of phospholipids. The phospholipid composition of luteal LD was surprisingly complex with more than 120 molecular 
A

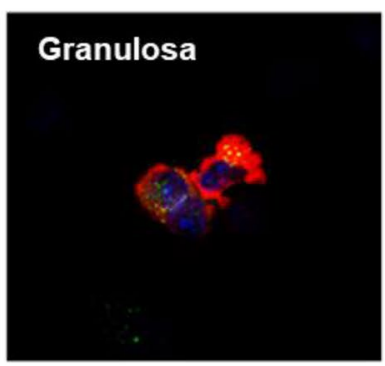

B

Hormone sensitive lipase

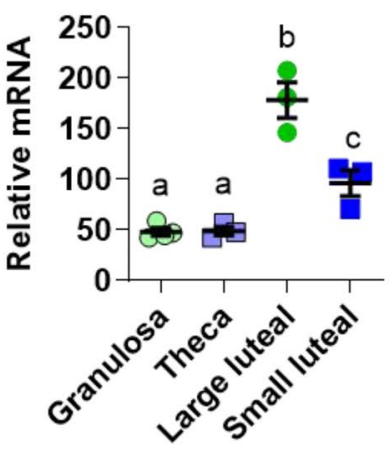

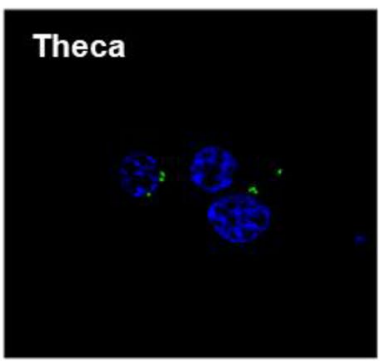

Perilipin 3

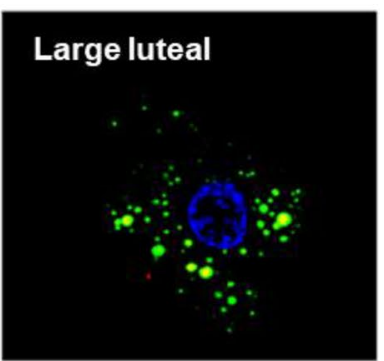

Perilipin 2

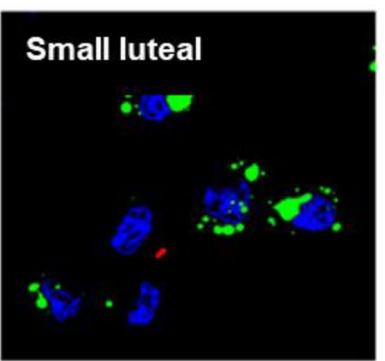

Steroidogenic acute regulatory protein
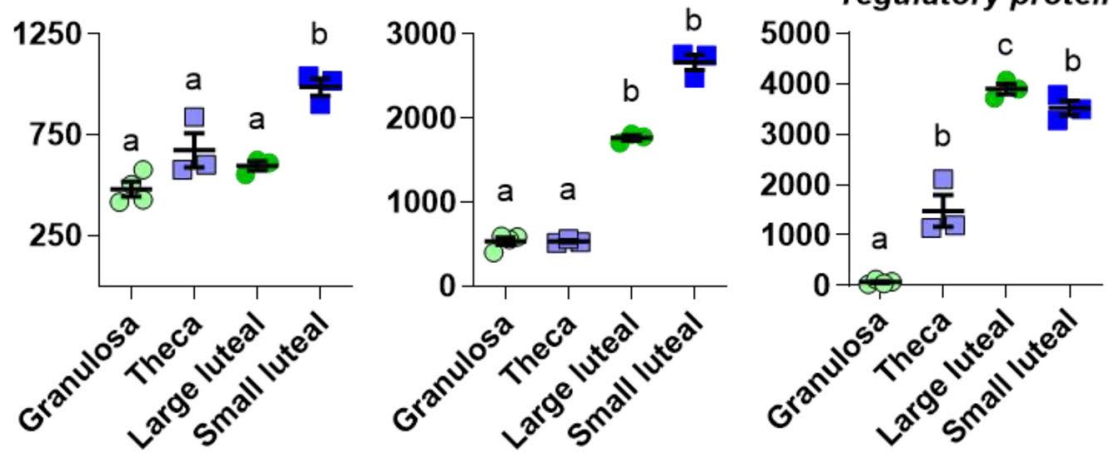

C

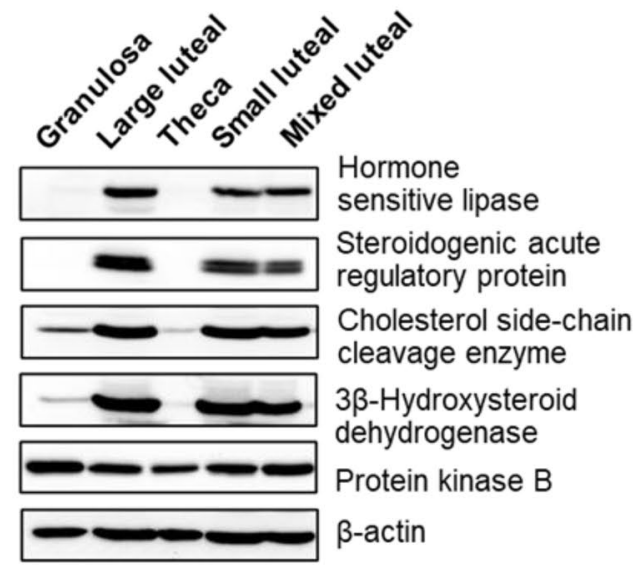

D
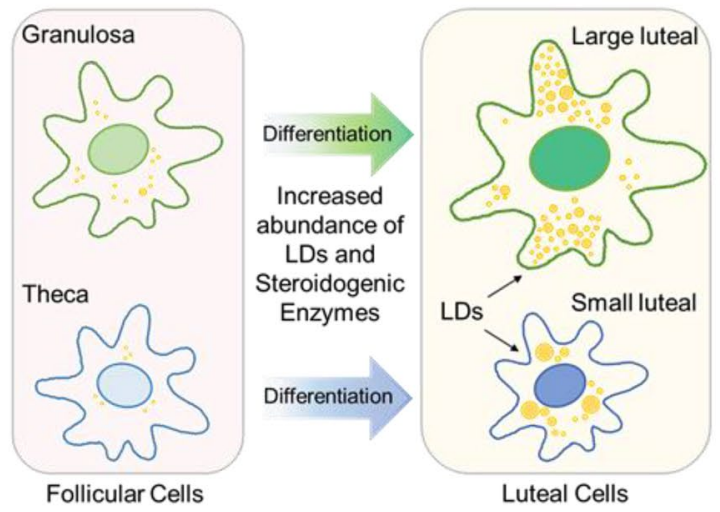

E

Triglycerides

Cholesteryl Esters
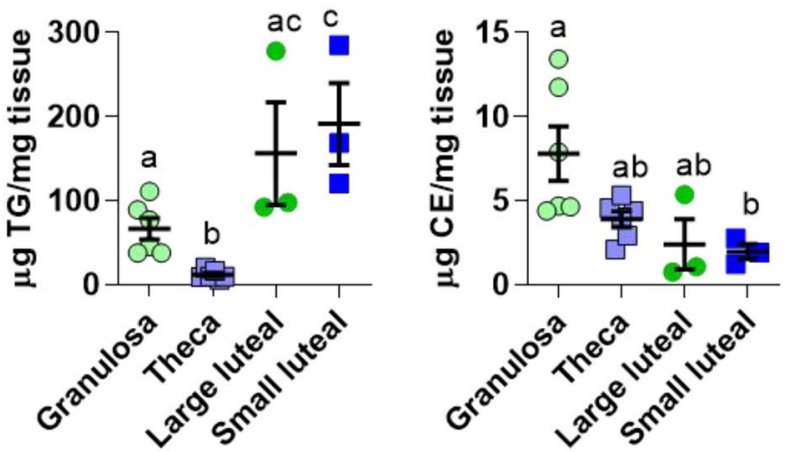

Sterols

Free Fatty Acids

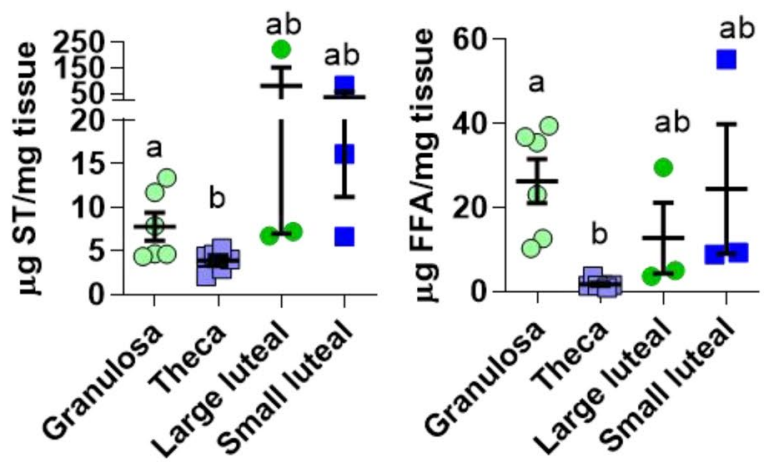

Figure 3. Comparison of follicular and luteal LD properties. Follicular granulosa cells, theca cells, large luteal cells, and small luteal cells were isolated from bovine ovaries as described in the Methods. Panel (A) Confocal fluorescent image showing LD staining in freshly isolated bovine granulosa, theca, large luteal, and small luteal cells. LDs were stained with the neutral lipid dye BODIPY 493/503 (green), and cells were immuno-labeled using an aromatase antibody to specifically label granulosa cells (red), and the nuclei are counter-stained with 4',6-diamidino-2-phenylindole (DAPI, blue). All images are equal magnification. Panel (B) Microarray analysis of mRNA abundance of LD-coat proteins: perilipin 2 and 3, cholesteryl esterase: hormone sensitive lipase, and steroidogenic marker: steroidogenic acute regulatory protein. Significance determined in (34). Means 
with different letters differ significantly between cell types $(P<0.05)$. Panel $(\mathbf{C})$ Western blot of LD-associated hormone sensitive lipase and steroidogenic enzymes in follicular granulosa and theca cells in comparison to large luteal, small luteal, and mixed luteal cells. Panel (D) Model depicting changes in LD number and proteins associated with luteal steroidogenesis during follicular cell differentiation. Panel (E) High-performance thin layer chromatography analysis of freshly isolated granulosa $(n=6)$, theca $(n=6)$, large luteal $(n=3)$ and small luteal cells $(n=3)$. Means \pm SEM overlay individual measurements, significance was determined using mixed effects model and Tukey's multiple comparisons test (factor 1: cell type (unmatched), factor 2: lipid class (matched)) after log transformation of values. Means with different letters differ significantly between cell types $(P<0.05)$

A

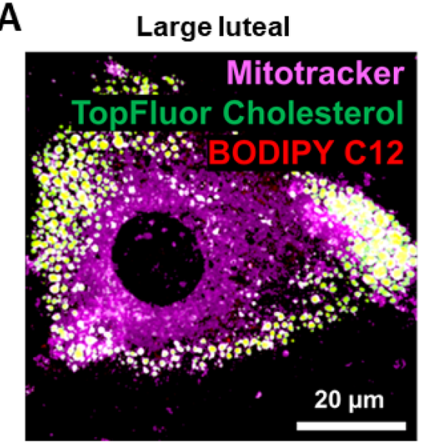

C

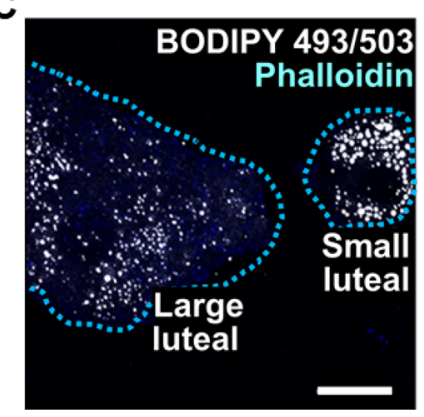

$\mathbf{F}$

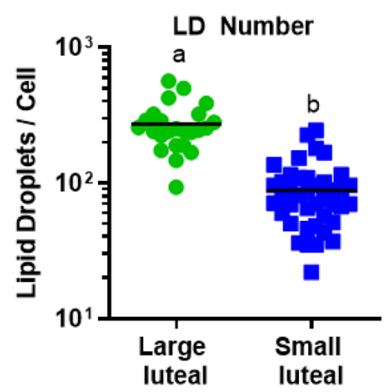

Small luteal

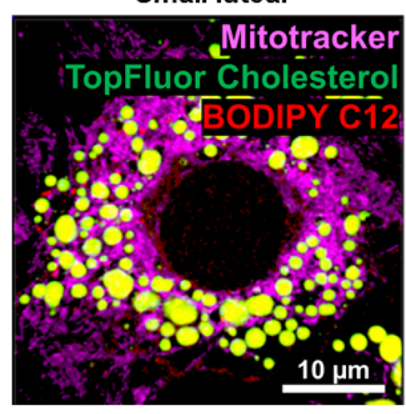

D

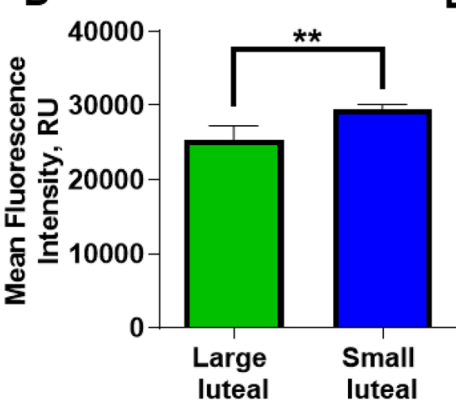

B Colocalization of TopFluor Cholesterol with BODIPY C12

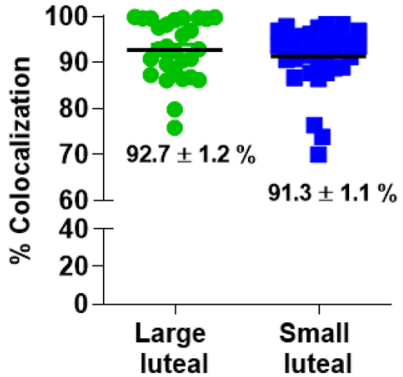

E

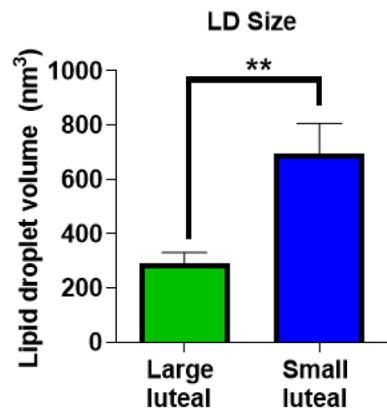

Figure 4. Differences in LDs between small and large luteal cells. Individual LD measurements in freshly isolated large luteal cells and small luteal cells were determined using confocal microscopy. Panel (A) Representative confocal micrographs of enriched large luteal and small luteal populations pre-loaded with BODIPY C12 and TopFluor Cholesterol for 48-h. Mitochondria (Mitotracker; magenta), TopFluor Cholesterol (green), and BODIPY C12 (red); Micron bars represent 20 and $10 \mu \mathrm{m}$, respectively. Panel (B) Quantitative analysis of percent colocalization of TopFluor Cholesterol with BODIPY C12 in large luteal cells (green) and small luteal cells (blue). Panel (C) Individual lipid droplet (LD) measurements in freshly isolated large and small luteal cells were determined after BODIPY staining of three-dimensional rendering of confocal images. Representative images of large luteal cells and small luteal cells. BODIPY 493/503 (white) and Phalloidin (blue); Dashed blue line indicates cell boundaries. Micron bar represents $20 \mu \mathrm{m}$. Panel (D) Quantitative analysis of mean fluorescence intensity for large luteal and small luteal cells. Significance of data was assessed with unpaired two-tailed t-test. Panel (E) Quantitative analysis of individual LD size, large luteal (25 individual cells), small luteal cells (41 individual cells) from 3 animals are displayed as mean \pm SEM. Panel (F) Logarithmic graph displaying the quantitative analysis of number of LDs per cell, significance was assessed using unpaired twotailed t-test after log transformation of the data. 
A

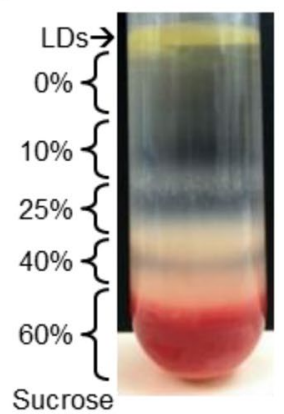

C

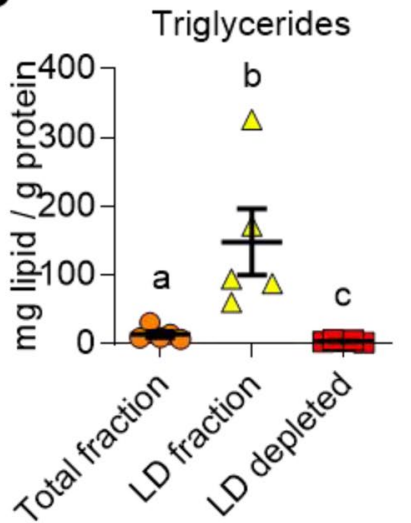

Free Fatty Acids
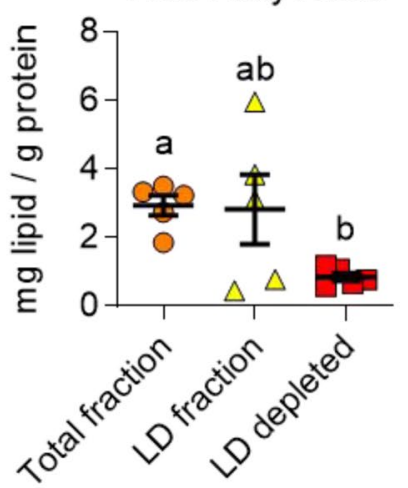

B

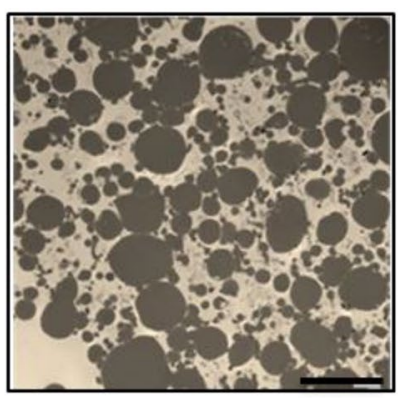

Figure 5. Isolated luteal LD properties. Sucrose gradient and ultra-centrifugation was used to isolate luteal LDs Transmission electron micrography images were obtained to validate successful isolation of luteal LDs. Panel (A) Representative image of luteal LDs and sucrose gradient fractions following ultra-centrifugation. Panel (B) Representative transmission electron micrograph from isolated LD preparations. Micron bar represents $6 \mu \mathrm{m}$. Panel (C) Lipid analysis by high-performance thin layer chromatography of whole luteal tissue fraction (total), LD fraction, and LD depleted post-nuclear supernatant. Lipid content of each fraction was normalized to protein content. Bars represent means \pm SEM, significance was determined using mixed-effects model and Tukey's multiple comparison test (factor 1: subcellular fraction (unmatched), factor 2: lipid class (matched)) after $\log$ transformation of values, $\mathrm{n}=5$. Means with different letters differ significantly between tissues $(P<0.05)$. species (85 detected in all three samples) in five classes (Fig. 6E). Analysis detected a total of 31 PC molecular species (22 detected in all three samples), with PC(34:1) contributing to $43 \%$ of the population and an additional $33 \%$ of the PC class was composed of PC(36:4), PC(38:4), and PC(38:5). Lipidomics detected 34 species of phosphatidylethanolamines (27 detected in all samples) which were dominated by phosphatidylethanolamine-linked fatty acids: (38:4), (36:2), (36:4), and (34:1). Twenty species of phosphatidylinositols were detected (16 in all three samples) with $72 \%$ of the total phosphatidylinositol pool was represented by phosphatidylinositol-linked fatty acids: (38:4), (40:5), and (38:5). Lipidomics detected 18 species of phosphatidylserines (13 in all three samples) with $76 \%$ of the total pool represented by phosphatidylserine-linked fatty acids: (40:5), (40:4), (36:1), and (38:3). 


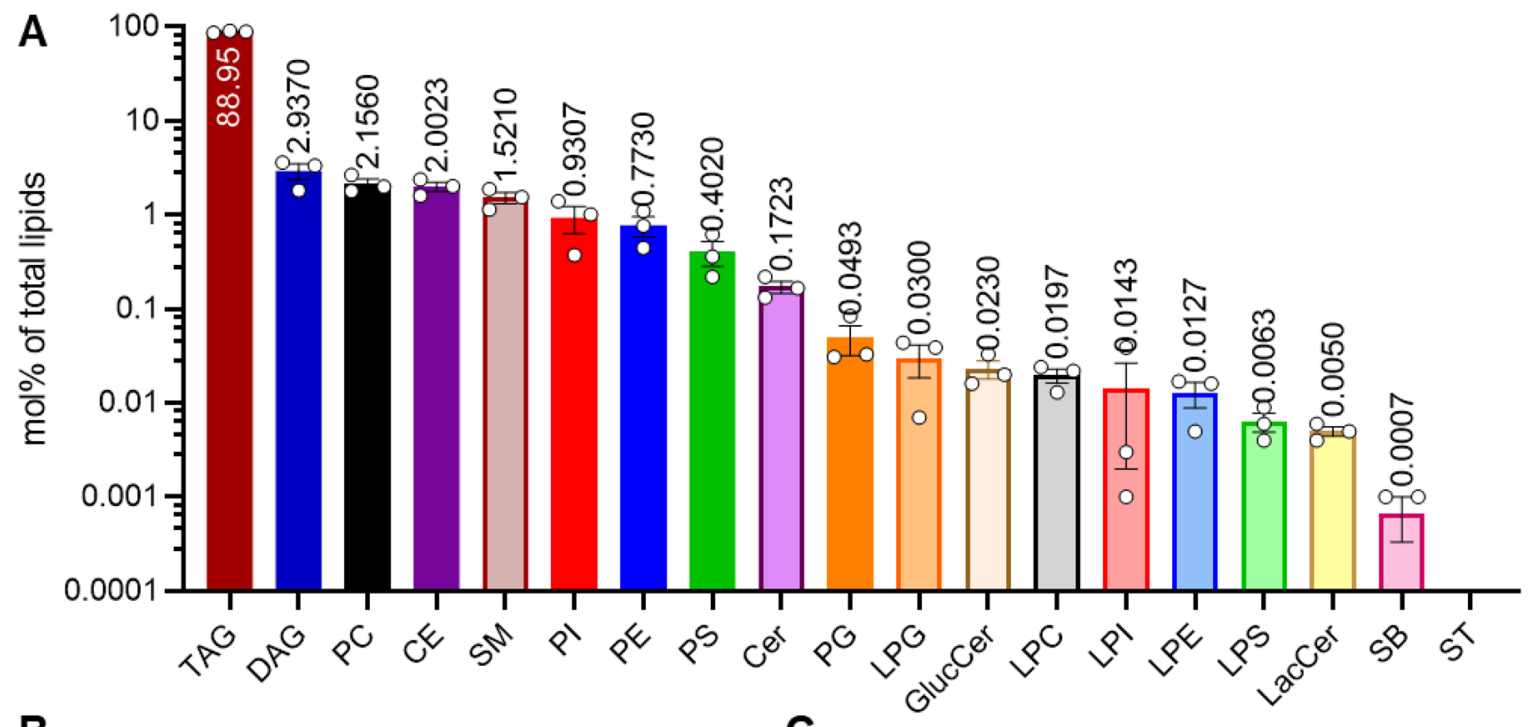

B

Triglyceride Fatty Acids

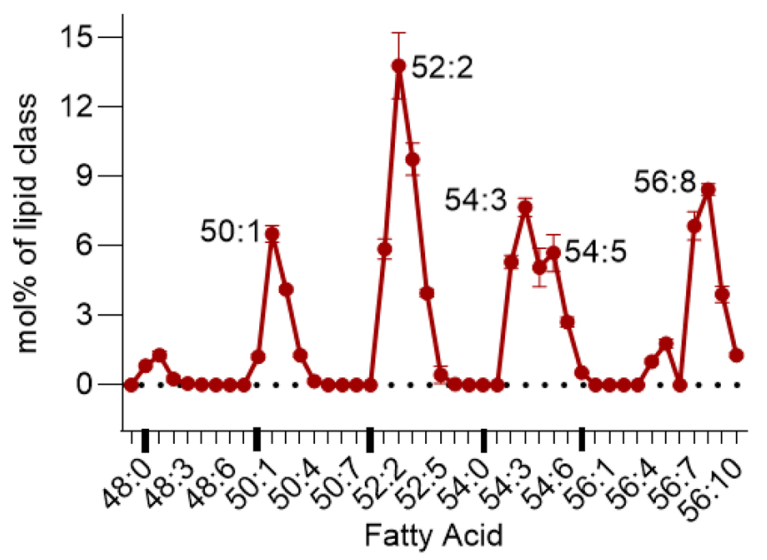

D

Cholesteryl Ester Fatty Acids

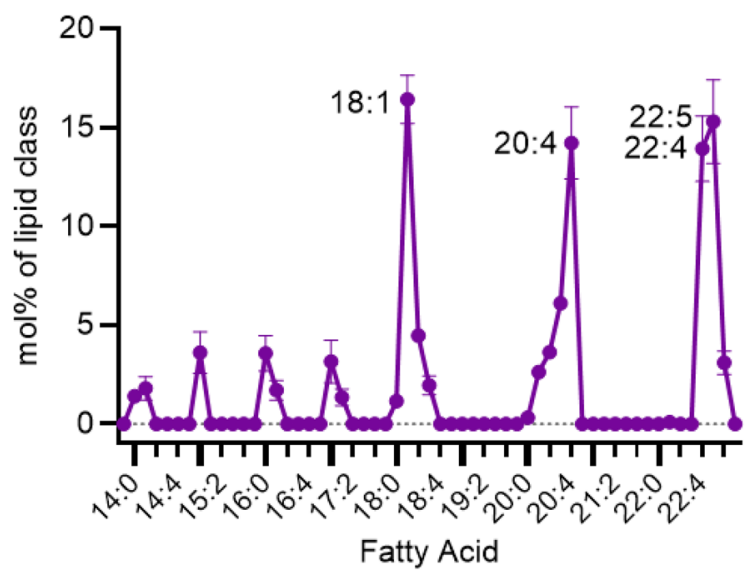

C

Diglyceride Fatty Acids

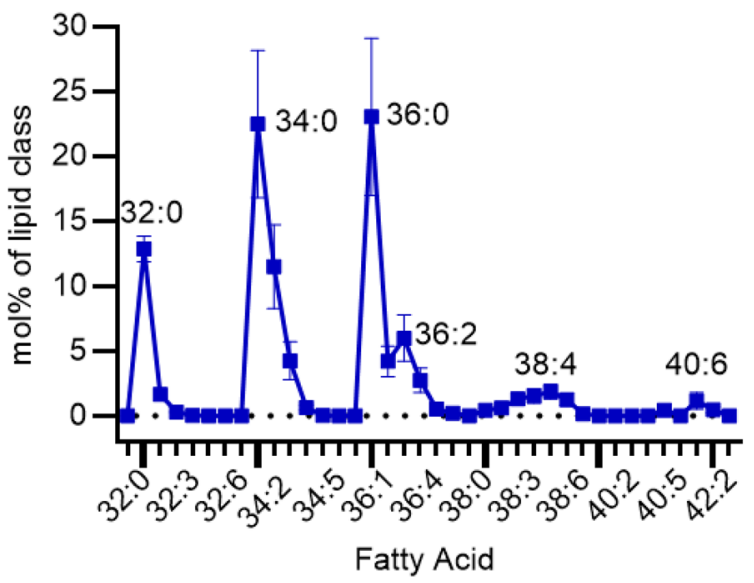

$\mathbf{E}$

Phospholipid Fatty Acids

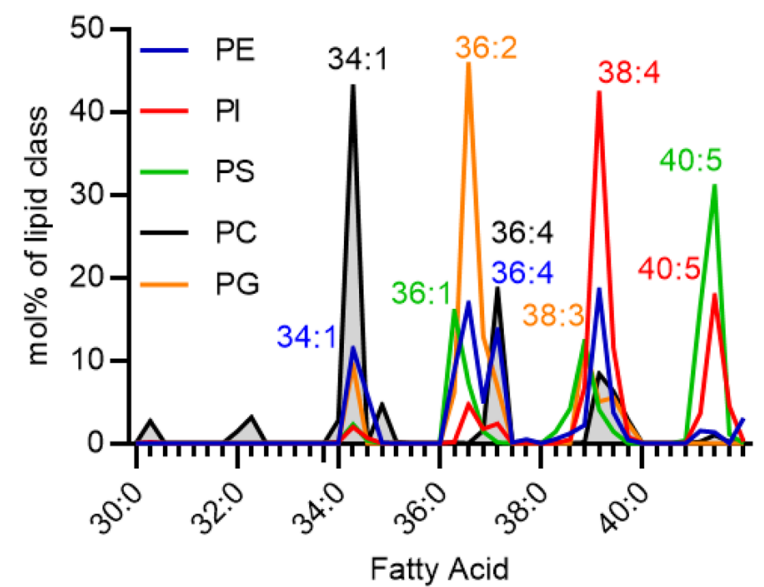

Figure 6. Lipidomic analysis of isolated luteal lipid droplets (LDs). LC/MS/MS with sMRM was used to detect lipid species with lipid class specific internal standards to allow for relative quantification. Panel (A) The top 18 lipid classes present in bovine luteal LDs are shown from the largest proportion of the total lipid fraction to the smallest as measured as the mol\% of the specific lipid class to the total lipid content, means \pm SEM overlay individual measurements, $n=3$. Cholesteryl Ester (CE); Glucosylceramide (GlucCer); sphingoid bases (SB). Panel (B) The combined fatty acid composition of TG in luteal LDs are represented as the mol\% within the TG class, with increasing degrees of saturation listed within the shortest to longest combined acyl chain length, peaks are labeled with the relevant fatty acid, points indicate means \pm SEM. Panel (C) The fatty acid 
composition of the diglycerides in luteal LDs are represented as the mol\% within the diglyceride class, points indicate means \pm SEM. Panel (D) The combined fatty acid composition of the cholesteryl esters in luteal LDs are represented as the mol\% within the cholesteryl ester class, points indicate means \pm SEM. Panel (E) The fatty acid composition of several phospholipid classes (Phosphatidylethanolamines (PE), Phosphatidylinositol (PI), Phosphatidylserine (PS), Phosphatidylcholines (PC) and Phosphatidylglycerol (PG)) in luteal LDs are represented as the mol\% within the appropriate lipid class, peaks are labeled with the relevant fatty acid, inflection points indicate means.

The phosphatidylglycerol class was composed of 14 species (7 detected in all samples) with phosphatidylglycerol (36:2) contributing to $46 \%$ of the total phosphatidylglycerol pool.

\section{Discussion}

Luteal LDs are a prominent feature of bovine luteal tissue and the presence, prominence, and composition of luteal LDs distinguish luteal tissue and luteal cells from other tissues and cell types. The large and small steroidogenic luteal cells contain these distinguishing LDs; with large luteal cells containing numerous small LDs, and small luteal cells processing fewer, but larger, LDs. Luteal LDs have a diameter of $200-1,100 \mathrm{~nm}$, confirmed by a variety of techniques including transmission electron microscopy, confocal microscopy, and phospholipid : total lipid ratio. Purified luteal LDs are rich in TG and contain cholesteryl esters, supporting the concept that luteal LDs have an important role in cellular metabolism and steroid biosynthesis by storing steroidogenic precursors.

Luteal tissue of all examined species contain abundant LDs, which vary in size and number throughout the normal estrous or menstrual cycle ${ }^{14-18}$. The findings that neutral lipids occupy approximately $5-16 \%$ of bovine luteal tissue area is in agreement with other studies examining LD to luteal cell area or volume ${ }^{26,27,33}$. In contrast, other tissues rarely contain the same extant of neutral lipids, except during pathological situations ${ }^{8-11}$. Likely, the area occupied by LDs in steroidogenic cells is even greater since luteal endothelial cells account for nearly $50 \%$ of total luteal cells $s^{34}$ but rarely contain $\mathrm{LDs}^{35}$. The present study and previous ultrastructural studies have noted the close contact of LDs with mitochondria ${ }^{16,20,22}$. The proximity of luteal LDs to mitochondria suggests that these organelles may function cooperatively to synthesize steroids ${ }^{6,36}$. The dynamics of LD and mitochondria interactions in luteal cells are unknown, but recent studies in other tissues implicate the mitochondrial targeting regions of PLIN $5^{37}$ and diacylglycerol O-acyltransferase 2 can facilitate physical interactions between mitochondria and $\mathrm{LDs}^{38}$. The emerging field of mitochondrial-associated membranes offers the possibility that there are regionalized areas of contact between mitochondria, endoplasmic reticulum and LDs ${ }^{39,40}$.

The size, distribution, protein, and lipid content of LDs can differ among various tissues ${ }^{7,36}$; therefore, expression of LD-associated proteins in bovine luteal tissue was compared with cardiac, hepatic, and adipose tissues. The tissues differed in the relative composition of PLINs and other lipid modifying enzymes, consistent with previous reports for adipose ${ }^{41}$ cardiac $^{42}$, and hepatic tissue ${ }^{10}$. Luteal tissue expressed PLIN2, PLIN3, PLIN5, hormone sensitive lipase, and 1-acylglycerol-3-phosphate O-acyltransferase ABHD5; and lower levels of adipose triglyceride lipase and sterol O-acyltransferase proteins, whereas, PLIN1 was undetectable. The presence of PLIN2, PLIN3, and PLIN5 suggest luteal LDs are metabolically active, oxidative, and mitochondrial-associated ${ }^{7}$. As well, bovine tissues differed in lipid composition. Bovine luteal tissue contained higher levels of TG than other tissues (cardiac, hepatic, \& pulmonary) with the unsurprising exception of adipose tissue. The high TG content of luteal tissue has unknown importance but could be the result of re-esterification of fatty acids liberated from cholesteryl esters during steroidogenesis to prevent fatty acid induced lipotoxicity. The unique LD-associated protein and lipid content of luteal LDs suggests luteal LDs have specialized lipid use and storage needs compared to other tissues.

After ovulation, the granulosa and theca cells of the follicle differentiate into the large and small luteal cells of the corpus luteum ${ }^{28,29}$. In contrast to the preovulatory follicle, which contains few $\operatorname{LDs}^{23,43}$, luteal tissue possesses numerous LDs. In this study, luteal tissue had fully established luteal LD content by three days post-ovulation; consistent with the idea that ovulation induces the formation of LDs during differentiation of the ovarian follicle into luteal tissue. Additionally, both large luteal cells and small luteal cells have abundant LDs and contain more TG in comparison to either granulosa or theca cells. These observations are in keeping with studies by Guraya et al., who described that following the luteinizing hormone surge, human granulosa cells develop fine "lipid granules" and "heterogeneous lipid bodies" within newly ruptured follicles, and that the theca interna cells of newly ruptured follicles fill with sudanophilic lipids, including cholesterol and cholesteryl esters ${ }^{23}$. As well, LD numbers and size increase in granulosa cells within a day after ovulation in rabbits ${ }^{43}$. Bovine luteal cells, in comparison to follicular cell types, have more LD-associated proteins, which parallel the increase in LD formation and steroidogenic capacity. Similarly, treatment of rhesus macaques with luteinizing hormone increases the amount of PLIN2 protein in granulosa cells within $12 \mathrm{~h}^{21}$. The program of cellular differentiation following ovulation resulting in luteinization of granulosa and theca cells is accompanied by increased expression of LD-associated proteins, elevation in TG, and formation of LDs in steroidogenic luteal cells.

The LDs of large and small luteal cells differ primarily in the number and size of LDs per cell, with minimal differences in lipid content and LD-associated mRNAs. Small luteal cells have a mean LD volume 2.4 times greater than large luteal cells; whereas, large luteal cells have three times the number of LDs present in small luteal cells. This finding is in agreement with data by Khanthusaeng et al., who reported that ovine large luteal cells have many smaller LDs and small luteal cells have fewer, but larger $\mathrm{LDs}^{33}$. The difference in LD size and number in the two cell types may relate to the different functions of large and small luteal cells. Bovine large luteal cells are responsible for secretion of large quantities of progesterone under basal conditions, whereas, small luteal cells secrete less progesterone under basal conditions but respond acutely to luteinizing hormone with robust increases in progesterone production ${ }^{44}$. Small LDs in large luteal cells could provide increased accessibility for continuous 
substrate utilization, such as liberation of cholesterol for constitutive steroid synthesis ${ }^{7}$. The larger LDs seen in small luteal cells could function primarily as a lipid storage mechanism, which can be accessed as needed, such as in response to hormones that stimulate steroidogenesis ${ }^{7}$.

Cholesteryl esters and TGs are almost exclusively located in luteal LDs. Bovine luteal LDs contain primarily TG ( $89 \%$ of total lipid content), and are relatively cholesteryl ester-poor $(3.7 \pm 0.7 \mathrm{pmol} / \mu \mathrm{g}$ protein; $2 \%$ of total lipid), findings similar to whole bovine luteal tissue ${ }^{24}$. Although cholesteryl esters and TG can segregate into distinct LD populations ${ }^{30}$, the LDs in large or small luteal cells show little segregation of TG and cholesteryl esters, which may reflect species or cell type differences. In contrast to bovine luteal tissue, luteal tissue from rabbits and rats is cholesteryl ester-rich ${ }^{25}$. However, bovine luteal tissue does not rely on de novo cholesterol synthesis for progesterone synthesis ${ }^{45}$; therefore, a small pool of cholesteryl esters may be sufficient for luteal function. The high TG content in bovine luteal LDs may serve as a substrate for energy production to fuel the steroidogenic output of luteal tissue. The fatty acids derived from cholesteryl esters may be converted to biologically active lipid mediators, re-esterified and stored in LDs or cell membranes, or used for $\beta$-oxidation, ultimately producing acetyl-CoA for the citric acid cycle. It seems likely that the production of large quantities of progesterone by luteal cells could require $\beta$-oxidation of fatty acids to provide the energy needed for optimal steroidogenesis.

Mass spectrometry was used to obtain detailed information about the lipid composition of bovine luteal tissue LDs. LDs are composed of a core consisting of neutral lipids (TGs and cholesteryl esters) bound by a monolayer of phospholipids ${ }^{7}$. The phospholipid composition of isolated droplets is remarkably complex. Luteal LD phospholipid composition (expressed as a percentage of total phospholipid) of luteal LDs is predominantly PC (45\%) followed by sphingomyelins (22\%), phosphatidylinositols (13\%) and phosphatidylethanolamines (11\%). In contrast, phospholipid content of hepatic LD from fed animals was largely PC (61\%) and phosphatidylethanolamines $(23 \%)$ with lesser amounts of phosphatidylinositols and sphingomyelins. The present results also differ somewhat from a report on the phospholipid content of LDs isolated from various cells lines following incubation with oleate to induce LD formation; the LD were predominately PC rich followed by phosphatidylethanolamine and phosphatidylinositol, as noted above, but were deficient in sphingomyelins and phosphatidylserines ${ }^{31,46,47}$. When directly compared, luteal LDs had $\sim 15$-fold more sphingomyelins and $\sim 8.5$-fold more phosphatidylserines than either mouse hepatic tissue or CHO K2 cells ${ }^{31,46,47}$. Despite the tissue and cell type differences in lipid class abundance, analysis of the specific TG, DG, PC, phosphatidylethanolamine and phosphatidylinositol species revealed that the constituent fatty acids within each phospholipid class are similar to previous studies ${ }^{31,46,47}$.

In steroidogenic tissues, the hydrolysis of cholesterol esters by hormone sensitive lipase yields cholesterol and a free fatty acid. The cholesterol serves as a precursor for mitochondrial steroid synthesis ${ }^{48}$, and while the fate of the fatty acid is unknown, it could be converted to biologically active lipid mediators, re-esterified and stored in LDs or membranes, or used for energy production. The cholesteryl esters in bovine luteal LDs are primarily $(60 \%)$ mono- and polyunsaturated fatty acids evenly distributed among oleic acid, and the omega-3 and omega-6 20:4, 22:4 and 22:5 fatty acids. This differs from ovine luteal cholesterol ester fatty acids which are predominantly palmitic acid [(16:0), 30.7\%], oleic acid [(18:1) 22.3\%] and linoleic acid [(18:2) 17.5\%] ${ }^{15}$. Cholesteryl ester fatty acid content of rat luteal tissue had many similarities to those in bovine luteal LDs but contained more palmitic acid (16:0), and less oleic and arachidonic acids (18:1 and 20:4) content, and a reversed ratio of 18:0 to 18:1 fatty acids. The differences in fatty acid composition among these species could be a reflection of species or diet effects ${ }^{14}$.

This study described in detail the extent, size, number and content of LDs in bovine luteal tissue and steroidogenic cells. The study also examined the increases in LD-associated proteins and lipids that occur during the follicle to luteal transition. Further research examining the impact of obesity, undernutrition and polycystic ovary syndrome on luteal LDs may provide insights into mechanisms of infertility and disorders of steroidogenesis. Additional studies examining the LDs in theca and granulosa cells and the mechanisms controlling the onset of LD presence in luteal cells could reveal their role in steroid production. Luteal LDs likely play a critical role in progesterone production by storing cholesteryl esters and interacting with mitochondria and endoplasmic reticulum to optimize steroid synthesis and provide substrates for energy production.

\section{Materials and methods}

Animals. Non-lactating beef cows between 2-6 years in age $(n=15)$ of composite breeding [75\% Red Angus and 25\% MARC III (1/4 Angus, 1/4 Hereford, 1/4 Pinzgauer, 1/4 Red Poll)] from the beef physiology herd at the University of Nebraska Agricultural Research and Development Center were synchronized using a modified 7-day CO-Synch protocol that utilizes GnRH and a controlled internal drug release device (CIDR; $1.38 \mathrm{~g}$ progesterone, Zoetis, Florham Park, NJ) to synchronize animal estrous cycles. The CIDR is removed after 7 days and animals administered prostaglandin F2a (25 mg; Lutalyse, i.m., Zoetis Inc., Kalamazoo, MI). A second GnRH injection was administered $36 \mathrm{~h}$ after prostaglandin $\mathrm{F} 2 \alpha$ and 3 or 10 days post-GnRH injection, 3-5 cows were subjected to a bilateral ovariectomy. Ovaries were removed via a right-flank approach paralumbar fossa laparotomy, to avoid the rumen and prevent internal hemorrhaging, as previously detailed ${ }^{49,50}$. Luteal tissue was prepared for microscopy and remaining tissue was snap frozen using liquid $\mathrm{N}_{2}$. Day 10 corpora lutea weighed significantly more than day 3 corpora lutea ( $4.7 \pm 0.46$ vs. $2.8 \pm 0.65$ g, respectively). However, in all other measures examined there were no significant differences. Therefore, data from both day 3 and day 10 were pooled to provide additional statistical power and narrow the confidence intervals associated with the progesterone-secreting bovine corpora lutea. The University of Nebraska-Lincoln IACUC committee preapproved all animal procedures and all procedures were performed in accordance with the guidelines and regulations of the approved IACUC protocols and with Animal Research: Reporting in vivo Experiments ${ }^{51}$. 


\begin{tabular}{|l|l|l|l|l|}
\hline Antibody name & Dilution & Source & Supplier (distributor, town, country) & Cat. No \\
\hline Perilipin 1 & $1: 1,000$ & Rabbit pAB & $\begin{array}{l}\text { Sigma Life Science (St. Louis, Missouri, } \\
\text { USA) }\end{array}$ & HPA024299 \\
\hline Perilipin 2 & $1: 1,000$ & Rabbit pAB & $\begin{array}{l}\text { Novus Biologicals (Centennial, Colorado, } \\
\text { USA) }\end{array}$ & NB110-40877 \\
\hline Perilipin 3 & $1: 1,000$ & Rabbit pAB & Abcam (Cambridge, United Kingdom) & 47638 \\
\hline Perilipin 5 & $1: 1,000$ & Guinea Pig pAB & Progen Biotechnik (Heidelberg, Germany) & GP31 \\
\hline Adipose triglyceride lipase & $1: 1,000$ & Rabbit pAB & $\begin{array}{l}\text { Cell Signaling (Danvers, Massachusetts, } \\
\text { USA) }\end{array}$ & 2138 S \\
\hline Abhydrolase domain containing 5 & $1: 1,000$ & Mouse mAB & Novus Biologicals & H00051099-M01 \\
\hline Hormone Sensitive Lipase & $1: 1,000$ & Rabbit pAB & Cell Signaling & 41075 \\
\hline Sterol O-acyltransferase 1 & $1: 1,000$ & Rabbit pAB & Abcam & ab72229 \\
\hline $\begin{array}{l}\text { Glyceraldehyde 3-phosphate dehydroge- } \\
\text { nase }\end{array}$ & $1: 1,000$ & Mouse mAB & $\begin{array}{l}\text { EMD Millipore (Burlington, Massachu- } \\
\text { setts, USA) }\end{array}$ & MAB374 \\
\hline Aromatase & $1: 200$ & Rabbit pAB & Abcam & ab80206 \\
\hline 3 beta-hydroxysteroid dehydrogenase & $1: 1,000$ & Rabbit mAB & A gift from Dr. Ian Mason & \\
\hline$\beta$-actin & $1: 5,000$ & Mouse mAB & Sigma Life Science & A5441 \\
\hline$\alpha$-rabbit HRP-linked & $1: 10,000$ & & Jackson Research (West Grove, PA, USA) & $111-035-003$ \\
\hline$\alpha$-guinea pig HRP-linked & $1: 10,000$ & & Jackson Laboratory & $106-035-003$ \\
\hline$\alpha$-mouse HRP-linked & $1: 10,000$ & & Jackson Laboratory & $115-035-205$ \\
\hline$\alpha$-rabbit Alexa Fluor 594 & $1: 500$ & & Invitrogen (Carlsbad, CA, USA) & A-11012 \\
\hline Mitotracker Deep Red FM & $500 \mathrm{nM}$ & & Thermo Fisher (Carlsbad, CA, USA) & M22426 \\
\hline Phalloidin & $1: 500$ & & Thermo Fisher & A34055 \\
\hline BODIPY 493/503 & $20 \mu \mathrm{M}$ & & Thermo Fisher & D3922 \\
\hline BODIPY FL C 12 & $1 \mu \mathrm{M}$ & & Thermo Fisher & D3822 \\
\hline TopFluor Cholesterol & $5 \mu \mathrm{M}$ & & $\begin{array}{l}\text { Avanti Polar Lipids (Alabaster, Alabama, } \\
\text { USA) }\end{array}$ & 810255 \\
\hline DAPI & & Thermo Fisher & D1306 \\
\hline
\end{tabular}

Table 1. Characteristics of antibodies and reagents used for western blotting and microscopy. ${ }^{\mathrm{a}}{ }^{\prime}, 6$-diamidino2-phenylindole (DAPI).

LD staining in luteal tissue. Tissue sections were frozen in OCT (Tissue-Tek) and transported on dry ice. Frozen samples were kept at $-80^{\circ} \mathrm{C}$ until sectioning using a Leica CM3050S instrument and attached to silanecoated slides before fixation in $10 \%$ phosphate-buffered formalin for $1 \mathrm{~h}$. Select fixed slides were stained with oil red $\mathrm{O}$ and counterstained with Harris' hemotoxin using an automated slide staining set up at the University of Nebraska Medical Center Tissue Sciences Facility. Slides were scanned at $40 \times$ using Ventana's Coreo Au Slide Scanner. Images were analyzed by Definiens Tissue Studio (Munich, Germany) to quantify nuclei number and area occupied by oil red $\mathrm{O}$.

Coronal sections (through the stomata) of luteal tissue were fixed in $3 \%(\mathrm{w} / \mathrm{v})$ paraformaldehyde and $0.2 \%$ glutaraldehyde in $\mathrm{PBS}, \mathrm{pH} 7.4$, post-fixed in $2 \% \mathrm{OsO}_{4}$, resin-embedded, and ultra-thin sectioned for electron microscopy. Transmission electron microscopy images were captured using a Hitachi H7500 at the University of Nebraska Lincoln Center for Biotechnology. Three images (magnification: 8,000×) from luteal tissue from each animal were used for quantification of LD number and area using Image ${ }^{52}$.

Additional fixed luteal tissue slides were immunolabeled for a marker of steroidogenic cells, 3 beta-hydroxysteroid dehydrogenase/Delta 5-> 4-isomerase type 1, and incubated at $4{ }^{\circ} \mathrm{C}$ for $24 \mathrm{~h}$. Slides were washed 3 times with $0.1 \%$ Tween in PBS to remove unbound antibody and counterstained using appropriate secondary antibodies, BODIPY 493/503 and DAPI. Slides were washed again and mounted to glass microscope slides using Fluoromount-G (Electron Microscopy Sciences) and stored at $-20^{\circ} \mathrm{C}$ until imaging. Additional antibody and staining information are available in Table 1.

Isolation of granulosa, theca, large luteal, and small luteal cells. For luteal cell preparations, bovine ovaries were collected from a local abattoir during early pregnancy (fetal crown-rump length $<15 \mathrm{~cm}$ ) ${ }^{53}$, dissociated with collagenase, and centrifugal elutriation was performed to prepare enriched preparations of small and large luteal cells, as described previously ${ }^{54,55}$. The average purity of small luteal cells was $>90 \%$ and large luteal cells was $60 \% \pm 10 \%$.

Follicular granulosa and theca cell pools were prepared from bovine ovaries with large follicles $(>8 \mathrm{~mm}$ diameter) collected from a local abattoir. Ovaries were visually assessed for healthy-appearing follicles and the corresponding follicular fluid was confirmed to be $>0.8 \mathrm{~mL}$ and clear of blood and gross cellular contamination ${ }^{56}$. Follicular granulosa cells from approximately 10 follicles were suspended in DMEM/F12 culture media. After the granulosa cells were removed, the theca interna was removed with fine forceps. Granulosa cells were washed by centrifugation three times at $150 \mathrm{rcf}$ for 5-10 min and filtration through a $70 \mu \mathrm{m}$ nylon mesh. The theca interna were suspended in collagenase 2 (103 IU/mL, Atlanta Biologicals) in DMEM/F12 and dispersed using constant 
agitation at $37^{\circ} \mathrm{C}$ for $1 \mathrm{~h}$. Dispersed theca cells were removed from the undigested tissue by filtration through a $70 \mu \mathrm{m}$ mesh then washed by centrifugation three times at $150 \mathrm{rcf}$ for 5-10 min.

Microarray. Bovine gene expression arrays from NCBI GEO repository (GSE83524) were mined to analyze expression of expression of LD components in freshly isolated bovine granulosa $(n=4)$ and theca $(n=3)$ cells from large follicles and from purified preparations of bovine small $(n=3)$ and large $(n=3)$ luteal cells from mature corpora lutea. Details of the isolation and analysis were previously published ${ }^{29}$.

LD isolation from tissue. Bovine luteal, adipose, cardiac, hepatic and pulmonary tissues were obtained from a local abattoir. For luteal tissue, bovine ovaries were collected from a local abattoir during early pregnancy (fetal crown-rump length $<15 \mathrm{~cm})^{53}$. The tissues $(\sim 2.5 \mathrm{~g})$ were washed thoroughly in TE buffer $(10 \mathrm{mM}$ Tris, $1 \mathrm{mM}$ EDTA, pH 7.4). Tissue was minced in $10 \mathrm{~mL}$ tissue homogenate buffer (60\% sucrose w/v in TE buffer containing protease and phosphatase inhibitor cocktail) and homogenized with a Teflon Dounce homogenizer in a glass vessel. The post-nuclear supernatant fraction was obtained after centrifugation at $2000 \mathrm{rcf}$ for $10 \mathrm{~min}$. The supernatant was loaded into a $30 \mathrm{~mL}$ ultracentrifuge tube and overlaid sequentially with $40 \%, 25 \%, 10 \%$, and $0 \%$ sucrose $\mathrm{w} / \mathrm{v}$ in TE buffer containing protease and phosphatase inhibitor cocktails. Samples were centrifuged at $110,000 \mathrm{rcf}$ for $30 \mathrm{~min}$ at $4{ }^{\circ} \mathrm{C}$ with no brake in a Beckman Coulter Avanti J-20 XP ultracentrifuge using an SW 32 Ti rotor. LDs concentrated in a band at the top of the gradient were harvested and concentrated by centrifugation at $2000 \mathrm{rcf}$ for $10 \mathrm{~min}$ at $4{ }^{\circ} \mathrm{C}$. The protocol was modified from ${ }^{32,57}$.

Western blots. Western blots were performed as previously described ${ }^{54}$ with the antibodies and reagents described in Table 1.

Lipidomics. Lipids from luteal LDs were extracted using a standard Bligh and Dyer extraction protocol ${ }^{58}$ and then dried under a stream of nitrogen and sent to Avanti Polar Lipids for lipidomic profiling of free sterols, cholesteryl esters, TGs, DGs, phospholipids, and sphingolipids. The molecular species within each class were identified, quantified, and summed to report the average lipid profile of bovine luteal LDs. To provide resolution and quantitative ability beyond the mass resolution of the tandem quadrupole mass spectrometers employed, molecular species were resolved by reversed-phase liquid chromatography in the presence of class and sub-class specific internal standard compounds added to each sample. The compounds were detected by tandem multiple reaction monitoring MS/MS for mass specific fragment ions according to lipid class and molecular weight of the compound. Selectivity was further enhanced by scheduling the detection of each compound according to its elution from the high-performance liquid chromatography column, known as scheduled multiple reaction monitoring. The semi-quantization was calculated using the integrated area of each analyte's peak, divided by the appropriate internal standard peak area, and multiplied by the internal standards known concentration. Quantification of cholesterol and cholesteryl esters were directly calculated with standards and internal standards from calibration response curves. Lipid concentrations were normalized to the corresponding protein concentration of each sample and as mol \% relative to lipid class.

High performance thin layer chromatography. For lipid analyses, cell suspensions were extracted with chloroform-methanol (1:1). High-performance thin layer chromatography was performed as previously described with modification to a single solvent system [petroleum ether (b.p. $60-70{ }^{\circ} \mathrm{C}$ )-ethyl ether-acetic acid $(45: 5: 0.5)]^{59}$. The images were analyzed using UVP Vision Works LS software by calculating the area under the curve after lane-specific straight line background correction. A mixture of the following standard lipids was co-chromatographed: cholesterol, trioleate glyceride, cholesteryl palmitate, and oleic acid. Preliminary analyses were completed to establish the linearity of detection for each lipid class to ensure that lipids did not exceed the linear range for quantitation. For every plate of cellular lipids, five lanes of varying amounts of lipid standards were simultaneously run to generate standard curves for quantitation. The amount of each cellular lipid was expressed as $\mu \mathrm{g}$ lipid/mg cell protein or $\mu \mathrm{g}$ lipid/mg initial tissue mass. The protocol was adapted from ${ }^{60}$.

Confocal microscopy and analysis. To characterize LDs in small and large bovine luteal cells, thin-layer cell preparations for confocal microscopy of enriched small luteal cells $>90 \%$ and large luteal cells (purity range: 50-90\%; mean: 65.3 \pm 14.6 ) were prepared using a Cytofuge 2 (Beckman Coulter). Cells were then fixed with $10 \%$ neutral buffered formalin at $4{ }^{\circ} \mathrm{C}$ for $30 \mathrm{~min}$. Cells were stained with BODIPY 493/503 and phalloidin (Table 1 ) for $1 \mathrm{~h}$ at room temperature and mounted using Fluoromount-G.

To determine the colocalization of BODIPY C12 and TopFluor Cholesterol in luteal LDs, enriched small $\left(5 \mathrm{E} 04 \mathrm{cells} / \mathrm{cm}^{2}\right)$ or large $\left(2 \mathrm{E} 04 \mathrm{cells} / \mathrm{cm}^{2}\right)$ luteal cell cultures were seeded onto sterile No. 1 glass coverslips $(22 \times 22 \mathrm{~mm})$. Cells were treated with TopFluor Cholesterol and BODIPY C12 for $48 \mathrm{~h}$ to allow incorporation in LDs. Cells were then incubated in Mitotracker Deep Red for $45 \mathrm{~min}$ to label mitochondria (Table 1). Cells were then fixed with $4 \%$ paraformaldehyde at $4{ }^{\circ} \mathrm{C}$ for $30 \mathrm{~min}$ and mounted using Fluoromount-G. Images were collected using a Zeiss confocal microscope equipped with a $60 \times$ oil immersion objective $(1.4$ N.A) and acquisition image size of $512 \times 512$ pixel $(33.3 \mu \mathrm{m} \times 33.3 \mu \mathrm{m})$. Cells were randomly selected from each slide and $0.33 \mu \mathrm{m}$ slice $\mathrm{z}$-stacked images were generated from bottom to top of each cell. A 3-dimensional image of each cell was created, and the area of individual cells was determined using Zen software. Images were converted to maximum intensity projections and processed utilizing ImageJ (National Institutes of Health) analysis software. LD size and number were quantified with ImageJ using AnalyzeParticles function in threshold images, with size (square pixel) setting from 0.1 to 100 and circularity from 0 to 1 . Outputs were then converted into microns. For 
colocalization of BODIPY C12 and TopFluor Cholesterol, z-stack images were analyzed in Image J using the JACoP plugin as previously described ${ }^{61}$.

Statistical analysis. All data are presented as means \pm SEM. Data was evaluated for normal distribution and log transformed if necessary. Specifics of statistical testing are described in the relevant figure legends. Statistical analysis was performed using GraphPad Prism (GraphPad Software, Inc) except for the microarray data which was analyzed as previously described ${ }^{29}$.

\section{Data availability}

Lipidomics data: Metabolomics Workbench, ST001286, https://www.metabolomicsworkbench.org/data/DRCCM etadata.php?Mode=Study\&StudyID=ST001286. Microarray data: NCBI GEO repository, GSE83524, https:// www.ncbi.nlm.nih.gov/geo/query/acc.cgi?acc=GSE83524

Received: 14 February 2020; Accepted: 18 June 2020

Published online: 09 July 2020

\section{References}

1. Micks, E., Raglan, G. B. \& Schulkin, J. Bridging progestogens in pregnancy and pregnancy prevention. Endocr. Connect. 4, R81-92 (2015).

2. Stocco, C., Telleria, C. \& Gibori, G. The molecular control of corpus luteum formation, function, and regression. Endocr. Rev. 28, 117-149 (2007).

3. Stricker, R. et al. Establishment of detailed reference values for luteinizing hormone, follicle stimulating hormone, estradiol, and progesterone during different phases of the menstrual cycle on the Abbott ARCHITECT analyzer. Clin. Chem. Lab. Med. 44, 883-887 (2006).

4. Sartori, R., Haughian, J. M., Shaver, R. D., Rosa, G. J. M. \& Wiltbank, M. C. Comparison of ovarian function and circulating steroids in estrous cycles of Holstein heifers and lactating cows. J. Dairy Sci. 87, 905-920 (2004).

5. Hu, J., Zhang, Z., Shen, W. J. \& Azhar, S. Cellular cholesterol delivery, intracellular processing and utilization for biosynthesis of steroid hormones. Nutr. Metab. 7, 47 (2010).

6. Talbott, H. A. \& Davis, J. S. Lipid droplets and metabolic pathways regulate steroidogenesis in the corpus luteum. In The Life Cycle of the Corpus Luteum (ed. Meidan, R.) 57-78 (Springer International Publishing, Berlin, 2017). https://doi.org/10.1007/ 978-3-319-43238-0 4

7. Fujimoto, T. \& Parton, R. G. Not just fat: The structure and function of the lipid droplet. Cold Spring Harb. Perspect. Biol. 3, 1-17 (2011).

8. Yuan, Y., Li, P. \& Ye, J. Lipid homeostasis and the formation of macrophage-derived foam cells in atherosclerosis. Protein Cell 3, 173-181 (2012).

9. Zhang, X., Wang, Y. \& Liu, P. Omic studies reveal the pathogenic lipid droplet proteins in non-alcoholic fatty liver disease. Protein Cell 8, 4-13 (2017).

10. Natarajan, S. K. et al. Structure, function and metabolism of hepatic and adipose tissue lipid droplets: implications in alcoholic liver disease. Curr. Mol. Pharmacol. (2015).

11. Krahmer, N., Farese, R. V. \& Walther, T. C. Balancing the fat: Lipid droplets and human disease. EMBO Mol. Med. 5, 905-915 (2013).

12. Miller, W. L. Disorders in the initial steps of steroid hormone synthesis. J. Steroid Biochem. Mol. Biol. https://doi.org/10.1016/j. jsbmb.2016.03.009 (2016).

13. Deane, H. W. \& Andrews, J. S. A comparison of the staining of lipid droplets in the mouse ovary by the Schiff reaction and by the Ashbel-Seligman carbonyl reaction. J. Histochem. Cytochem. 1, 283-295 (1953).

14. Strauss, J. F., Seifter, E., Lien, E. L., Goodman, D. B. \& Stambaugh, R. L. Lipid metabolism in regressing rat corpora lutea of pregnancy. J. Lipid Res. 18, 246-258 (1977).

15. Waterman, R. A. Changes in lipid contents and fatty acid compositions in ovine corpora lutea during the estrous cycle and early pregnancy. Biol. Reprod. 38, 605-615 (1988).

16. Parry, D. M., Willcox, D. L. \& Thorburn, G. D. Ultrastructural and cytochemical study of the bovine corpus luteum. J. Reprod. Fertil. 60, 349-357 (1980).

17. Bloor, W. R., Okey, R. \& Corner, G. W. The relation of the lipids to physiological activity I. The changes in the lipid contet of the corpus luteum of the sow. J. Biol. Chem. 86, 291-306 (1930).

18. Kapoor, K., Singh, O. \& Pathak, D. Lipid distribution variations in different stages of cyclic corpus luteum of indian buffalo. J. Anim. Res. 8, 379-385 (2018).

19. Claesson, L. Quantitative relationship between gonadotrophic stimulation and lipid changes in the interstitial gland of the rabbit ovary. Acta Physiol. Scand. Suppl. 31, 23-51 (1954).

20. Dorlikar, A. V., Dhamani, A. A., Charde, P. N. \& Mohite, A. S. Ultrastructure of ovarian preantral follicles and corpus luteum in Indian flying fox Pteropus giganteus (Brünnich). Edorium J. Cell Biol. 1, 1-11 (2014).

21. Seachord, C. L., VandeVoort, C. \& Duffy, D. M. Adipose differentiation-related protein: a gonadotropin- and prostaglandinregulated protein in primate periovulatory follicles. Biol. Reprod. 72, 1305-1314 (2005).

22. Green, J. A. \& Maqueo, M. Ultrastructure of the human ovary. I. The luteal cell during the menstrual cycle. Am. J. Obstet. Gynecol. 92, 946-957 (1965).

23. Guraya, S. S. Histochemical study of granulosa and theca interna during follicular development, ovulation, and corpus luteum formation and regression in the human ovary. Am. J. Obstet. Gynecol. 101, 448-457 (1968).

24. Hafs, H. D. \& Armstrong, D. T. Corpus luteum growth and progesterone synthesis during the bovine estrous cycle. J. Anim. Sci. 27, 134 (1968).

25. Armstrong, D. T. \& Flint, A. P. Isolation and properties of cholesterol ester storage granules from ovarian tissues. Biochem. J. 134, 399-406 (1973).

26. Heath, E., Weinstein, P., Merritt, B., Shanks, R. \& Hixon, J. Effects of prostaglandins on the bovine corpus luteum: granules, lipid inclusions and progesterone secretion. Biol. Reprod. 29, 977-985 (1983).

27. Hawkins, D. E. et al. An increase in serum lipids increases luteal lipid content and alters the disappearance rate of progesterone in cows. J. Anim. Sci. 73, 541-545 (1995).

28. Meidan, R., Girsh, E., Blum, O. \& Aberdam, E. In vitro differentiation of bovine theca and granulosa cells into small and large luteal-like cells: Morphological and functional characteristics. Biol. Reprod. 43, 913-921 (1990).

29. Romereim, S. M. et al. Gene expression profiling of bovine ovarian follicular and luteal cells provides insight into cellular identities and functions. Mol. Cell. Endocrinol. 439, 379-394 (2017). 
30. Khor, V. K. et al. The proteome of cholesteryl-ester-enriched versus triacylglycerol-enriched lipid droplets. PLoS ONE 9, e105047 (2014).

31. Bartz, R. et al. Lipidomics reveals that adiposomes store ether lipids and mediate phospholipid traffic. J. Lipid Res. 48, 837-847 (2007).

32. Ding, Y., Wu, Y., Zeng, R. \& Liao, K. Proteomic profiling of lipid droplet-associated proteins in primary adipocytes of normal and obese mouse. Acta Biochim. Biophys. Sin. (Shanghai) 44, 394-406 (2012).

33. Khanthusaeng, V. et al. Lipid droplets in cultured luteal cells in non-pregnant sheep fed different planes of nutrition. Acta Histochem. 118, 553-559 (2016).

34. Lei, Z. M., Chegini, N. \& Rao, C. V. Quantitative cell composition of human and bovine corpora lutea from various reproductive states. Biol. Reprod. 44, 1148-1156 (1991).

35. Spanel-Borowski, K. Diversity of ultrastructure in different phenotypes of cultured microvessel endothelial cells isolated from bovine corpus luteum. Cell Tissue Res. 266, 37-49 (1991).

36. Shen, W.-J., Azhar, S. \& Kraemer, F. B. Lipid droplets and steroidogenic cells. Exp. Cell Res. 340, 209-214 (2016).

37. Kimmel, A. R. \& Sztalryd, C. Perilipin 5, a lipid droplet protein adapted to mitochondrial energy utilization. Curr. Opin. Lipidol. 25, 1 (2014).

38. Stone, S. J. et al. The endoplasmic reticulum enzyme DGAT2 is found in mitochondria-associated membranes and has a mitochondrial targeting signal that promotes its association with mitochondria. J. Biol. Chem. 284, 5352-5361 (2009).

39. Vance, J. E. MAM (mitochondria-associated membranes) in mammalian cells: Lipids and beyond. Biochim. Biophys. Acta 1841, 595-609 (2014).

40. Benador, I. Y., Veliova, M., Liesa, M. \& Shirihai, O. S. Mitochondria bound to lipid droplets: Where mitochondrial dynamics regulate lipid storage and utilization. Cell Metab. 29, 827-835 (2019).

41. Brasaemle, D. L., Dolios, G., Shapiro, L. \& Wang, R. Proteomic analysis of proteins associated with lipid droplets of basal and lipolytically stimulated 3T3-L1 adipocytes. J. Biol. Chem. 279, 46835-46842 (2004).

42. Wang, H., Lei, M., Hsia, R. \& Sztalryd, C. Analysis of lipid droplets in cardiac muscle. Methods Cell Biol. 116, 129-149 (2013).

43. Guraya, S. S. A histochemical study of pre-ovulatory and post-ovulatory follicles in the rabbit ovary. J. Reprod. Fertil. 15, 381-387 (1968).

44. Hansel, W., Alila, H. W., Dowd, J. P. \& Milvae, R. A. Differential origin and control mechanisms in small and large bovine luteal cells. J. Reprod. Fertil. Suppl. 43, 77-89 (1991).

45. Armstrong, D. T., Lee, T. P. \& Miller, L. S. Stimulation of progesterone biosynthesis in bovine corpora lutea by luteinizing hormone in the presence of an inhibitor of cholesterol synthesis. Biol. Reprod. 2, 29-36 (1970).

46. Chitraju, C. et al. Lipidomic analysis of lipid droplets from murine hepatocytes reveals distinct signatures for nutritional stress. J. Lipid Res. 53, 2141-2152 (2012).

47. Chitraju, C. et al. The impact of genetic stress by ATGL deficiency on the lipidome of lipid droplets from murine hepatocytes. J. Lipid Res. 54, 2185-2194 (2013).

48. Nestler, J. E., Bamberger, M., Rothblat, G. H. \& Strauss, J. F. Metabolism of high density lipoproteins reconstituted with [3H] cholesteryl ester and [14C]cholesterol in the rat, with special reference to the ovary. Endocrinology 117, 502-510 (1985).

49. Youngquist, R. S., Garverick, H. A. \& Keisler, D. H. Use of umbilical cord clamps for ovariectomy in cows. J. Am. Vet. Med. Assoc. 207, 474-475 (1995).

50. Summers, A. F. et al. Altered theca and cumulus oocyte complex gene expression, follicular arrest and reduced fertility in cows with dominant follicle follicular fluid androgen excess. PLoS ONE 9, e110683 (2014).

51. Kilkenny, C., Browne, W., Cuthill, I. C., Emerson, M. \& Altman, D. G. Animal research: Reporting in vivo experiments: The ARRIVE guidelines. Br. J. Pharmacol. 160, 1577-1579 (2010).

52. Schneider, C. A., Rasband, W. S. \& Eliceiri, K. W. NIH Image to ImageJ: 25 years of image analysis. Nat. Methods 9, 671-675 (2012).

53. Evans, H. E. \& Sack, W. O. Prenatal development of domestic and laboratory mammals: Growth curves, external eatures and selected references. Anat. Histol. Embryol. 2, 11-45 (1973).

54. Mao, D. et al. ATF3 expression in the corpus luteum: possible role in luteal regression. Mol. Endocrinol. 27, 2066-2079 (2013).

55. Mamluk, R., Chen, D., Greber, Y., Davis, J. S. \& Meidan, R. Characterization of messenger ribonucleic acid expression for prostaglandin F2 alpha and luteinizing hormone receptors in various bovine luteal cell types. Biol. Reprod. 58, 849-856 (1998).

56. Ireland, J. J., Murphee, R. L. \& Coulson, P. B. Accuracy of predicting stages of bovine estrous cycle by gross appearance of the corpus luteum. J. Dairy Sci. 63, 155-160 (1980).

57. Brasaemle, D. L. \& Wolins, N. E. Isolation of lipid droplets from cells by density gradient centrifugation. Curr. Protoc. Cell Biol. 72,1-13 (2016).

58. Bligh, E. G. \& Dyer, W. J. A rapid method of total lipid extraction and purification. Can. J. Biochem. Physiol. 37, 911-917 (1959).

59. Mangold, H. K. \& Malins, D. C. Fractionation of fats, oils, and waxes on thin layers of silicic acid. J. Am. Oil Chem. Soc. 37, 383-385 (1960).

60. Rizzo, W. B. et al. Abnormal fatty alcohol metabolism in cultured keratinocytes from patients with Sjögren-Larsson syndrome. J. Lipid Res. 49, 410-419 (2008).

61. Plewes, M. R. \& Burns, P. D. Effect of fish oil on agonist-induced receptor internalization of the PGF2a receptor and cell signaling in bovine luteal cells in vitro. Domest. Anim. Endocrinol. 63, 38-47 (2018).

\section{Acknowledgements}

This work was supported by the Agriculture and Food Research Initiative from the USDA National Institute of Food and Agriculture (NIFA) [2018-67012-29531 to MRP, 2014-67011-22280 Pre-doctoral award to HT, 201167015-20076; 2017-67015-26450 and 2013-67015-20965 to ASC, JRW and JSD]; USDA Hatch grants [NEB26202/W2112 to ASC, eNEB ANHL 26-213 to ASC and JRW, NEB 26-206 to ASC and JRW]; NIH grants HD087402 and HD092263 to JSD, the VA Nebraska-Western Iowa Health Care System, Department of Veterans Affairs, Office of Research and Development Biomedical Laboratory Research and Development funds [JSD]; and The Olson Center for Women's Health, Department of Obstetrics and Gynecology, University of Nebraska Medical Center, Omaha, NE [JSD]; National Institute for General Medical Science (NIGMS) [INBRE-P20GM103427-14, COBRE-1P30GM110768-01 to University of Nebraska Microarray Core and the Bioinformatics and Systems Biology Core]; and The Fred \& Pamela Buffett Cancer Center Support [P30CA036727 to University of Nebraska Microarray Core and the Bioinformatics and Systems Biology Core].

\section{Author contributions}

H.A.T. designed and performed experiments, analyzed data, wrote the manuscript. M.R.P. designed and performed experiments, analyzed data, edited the manuscript. C.K., X.H., P.Z. performed experiments. W.B.R. provided expert guidance for lipid analyses, analyzed data. J.R.W., A.S.C. managed animal protocols and tissue 
acquisition, and edited the manuscript. J.S.D. designed and oversaw experiments, analyzed data, and edited the manuscript.

\section{Competing interests}

The authors declare no competing interests.

\section{Additional information}

Supplementary information is available for this paper at https://doi.org/10.1038/s41598-020-68091-2.

Correspondence and requests for materials should be addressed to J.S.D.

Reprints and permissions information is available at www.nature.com/reprints.

Publisher's note Springer Nature remains neutral with regard to jurisdictional claims in published maps and institutional affiliations.

(c) (i) Open Access This article is licensed under a Creative Commons Attribution 4.0 International License, which permits use, sharing, adaptation, distribution and reproduction in any medium or format, as long as you give appropriate credit to the original author(s) and the source, provide a link to the Creative Commons license, and indicate if changes were made. The images or other third party material in this article are included in the article's Creative Commons license, unless indicated otherwise in a credit line to the material. If material is not included in the article's Creative Commons license and your intended use is not permitted by statutory regulation or exceeds the permitted use, you will need to obtain permission directly from the copyright holder. To view a copy of this license, visit http://creativecommons.org/licenses/by/4.0/.

This is a U.S. Government work and not under copyright protection in the US; foreign copyright protection may apply 2020 